\title{
MMW-ONLINE-SPRECHSTUNDE
}

\author{
Kompetente Antworten innerhalb von 48 Stunden! \\ Unsere Experten beantworten medizinische \\ Fragen, die sich in Ihrem Praxisalltag ergeben.
}
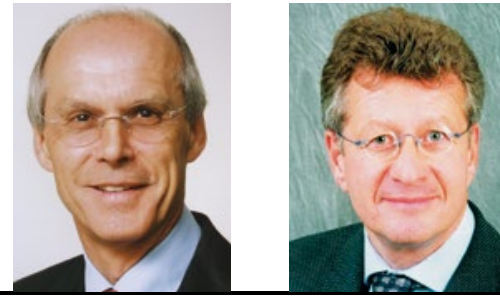

\section{Hilft Johanniskraut gegen Aura und Vertigo?}

? Dr. Volker Scheidemandel: In der deutschen Literatur finde ich wenig zum neurologischen Problem der Migräne im höheren Alter. Nun leidet eine 74-jährige Verwandte zunehmend - ca. 3- bis 4-mal pro Monat unter einer Aura und Vertigo, hat dabei allerdings kaum Kopfschmerzen. Sie ist Nichtraucherin, normalgewichtig, sportlich und ernährt sich mediterran. Allerdings ist sie seit ein paar Jahren öfter leicht depressiv und $a b$ und zu hyperaktiv. Sie meint, dass sie früher schon mal von hochdosiertem Johanniskraut profitiert habe, das sie derzeit nicht nimmt. Reicht hier Jo-

\begin{abstract}
hanniskraut? Und wenn ja: Sollte man es durchgehend geben? Übrigens ist sie wegen einer familiären Hypercholesterinämie erfolgreich eingestellt auf täglich $10 \mathrm{mg}$ Atorvastatin in Kombination mit $10 \mathrm{mg}$ Ezetimib.
\end{abstract}

!

MMW-Experte Dr. Stiefelhagen: Die beschriebene Symptomatik könnte zu einer larvierten Depression passen. Wenn die Patientin schon früher einmal gute Erfahrungen mit Johanniskraut gemacht hat, so spricht nichts dagegen, dieses Medikament wieder einzusetzen. Auch eine Dauertherapie ist unproblematisch.

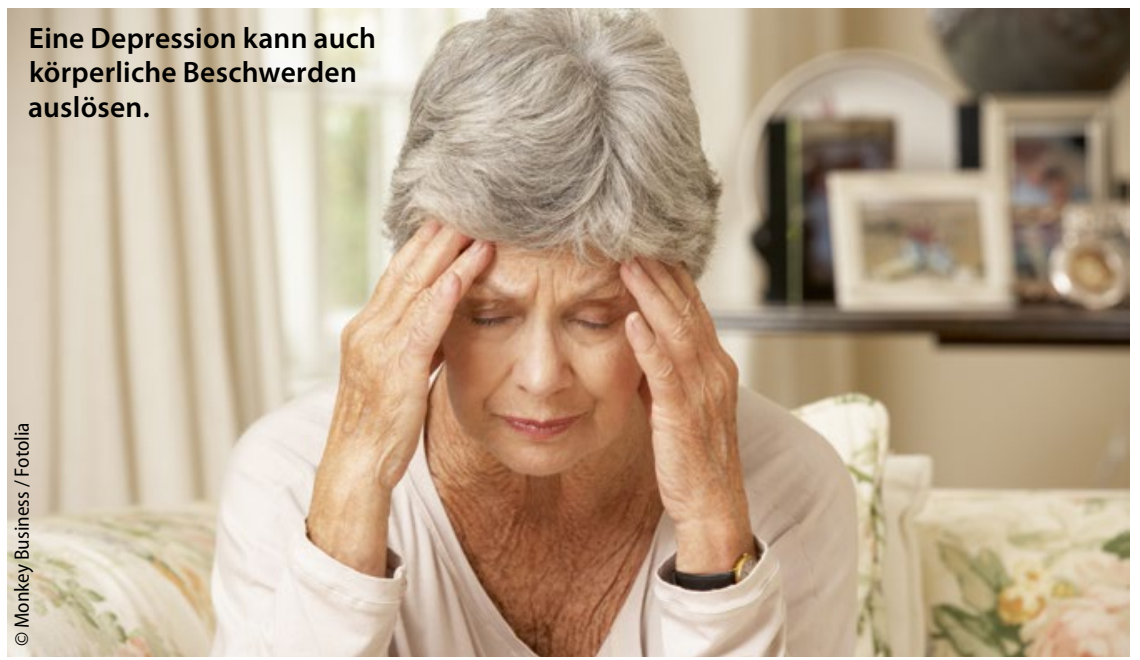

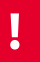
MMW-Experte Prof. FüeßI: Migräne kann zwar grundsätzlich in jedem Alter beginnen, in den meisten Fällen tritt der erste Anfall aber im Alter zwischen dem 10. und 20. Lebensjahr auf. Nur etwa $1 \%$ der Betroffenen erlebt ihn jenseits des 50. Lebensjahres. Frauen sind in dieser Altersgruppe doppelt so häufig betroffen wie Männer. Bei vielen Patienten, die lebenslang unter Migräne gelitten haben, bessern sich die Zustände mit zunehmendem Alter eher.

Wenn Kopfschmerzen bei älteren Menschen erstmals auftreten, so handelt es sich oft um sekundäre oder symptomatische Kopfschmerzen, die Anlass $\mathrm{zu}$ einer gründlichen neurologischen Untersuchung geben sollten. Kopfschmerzen bei älteren Personen können auch durch Hypertonie, Probleme beim Kauen aufgrund eines schlechten Zahnstatus oder schlecht angepasste Brillengläser bedingt sein. Schließlich sollte man auch immer an eine Arteriitis temporalis denken.

Gegen einen erneuten Versuch mit Johanniskraut spricht im vorliegenden Fall nichts. Im Gegenteil, die früheren positiven Erfahrungen sollten einen darin bestärken. Auf die mögliche Induktion der Aktivität von CYP 3A4 durch Johanniskraut sei hingewiesen, insbesondere bei gleichzeitiger Einnahme von Atorvastatin. 